\title{
Beverage Sales and Drinking and Driving: The Role of On-Premise Drinking Places.
}

\author{
by Paul J. Gruenewald, Tim Stockwell, Andrea Beel and Elena V. Dyskin
}

\section{@ COPYRIGHT 1999 Alcohol Research Doc umentation, Inc.}

ABSTRACT. Objective: The relationships between on-premise drinking places, beverage specific alcohol sales and drinking and driving were examined in a time series cross-sectional study of place-of-last-drink data from Perth, Western Australia. Method: At arrest, 2,411 drinking drivers reported their last location of consumption. Tabulated by 57 premises over 4 years, the rates at which individual premises were referenced as the place-of-last-drink were taken to reflect the relative distributions of numbers of drinking drivers coming from different premise types (hotels, taverns and nightclubs). The data were then statistically related to measures of premise types and characteristics and beverage specific alcohol sales. Results: Significant cross-sectional relationships were obtained between measures of premise types, alcohol sales and drinking and driving. Greatest numbers of drinking drivers came from taverns and from places selling greater amounts of beer and spirits. Significant longitudinal effects were obtained for sales of beer, proportions of high alcohol beer sold and sales of spirits. Conclusions: As a whole, the results suggest that, at least for Western Australia, outlets selling greater amounts of beer and spirits, and greater amounts of high alcohol beer, will produce larger numbers of drinking drivers. (J Stud. Alcohol 60: 47-53, 1999)

EMPIRICAL ASSESSMENTS of the relationships between alcoholic beverage preferences, use of drinking places and drinking and driving have relied upon a single source of primary data, self-reports of beverage and premise use. These have been obtained from drunken-driving offender and treatment populations (Perrine, 1970; Seizer et al., 1977), from driving populations at roadside (Borkenstein et al., 1964) and from general population studies (Casswell et al., 1993; Gruenewald et al., 1995; Single and Wortley, 1993; Stockwell et al., 1993). While all have noted the apparent cultural link between beer consumption and drinking and driving (see Berger and Snortum, 1986; Snortum et al., 1987), none has explicated the degree to which drinking and driving is separately related to beverage-specific use versus choice of drinking locations.

In recent years there has also been considerable concern expressed among the states of Australia regarding the consumption of high alcohol beers and the relationship of this form of consumption to drinking and driving. In Australia, drinking and driving is associated with approximately one-third of people killed and one-fifth of people injured on the road (Haworth and Rechnitzer, 1993). It has also been asserted that much of this activity is associated with the consumption of high versus low alcohol beers (Stockwell et al., 1992a) at specific premise locations (Stockwell et al., 1992b). In Perth, Western Australia, approximately half of those apprehended for drinking and driving have consumed their last drink on licensed premises (Land and Stockwell, 1991). With the introduction of low alcohol beers to Australia, there has been some expressed shift in beverage preferences among consumers (Makkai and McAllister, 1993); however, the degree to which high (versus low) alcohol beer consumption is related to drinking and driving per se is unknown. Attempts to separate out the effects of choice of drinking location and beverage preferences have suggested that the consumption of low alcohol beer is, indeed, related to reduced rates of drinking and driving, but that risks of drinking and driving may, nonetheless, be tied to drinking locations (with greatest risk occurring among drinkers at nightclubs; Beel et al., 1993).

One way to think about the relationships between premise types, alcohol sales and drinking and driving is to imagine that each drinking location is a source of alcohol to which drinkers are attracted and from which drinking drivers emerge. At each location the flow of alcohol reflects both the number of drinkers served and the quantities consumed by these drinkers. After leaving these establishments drinking drivers appear on the road over evening hours, providing targets for arrest by police. If these drivers were asked where they had drunk alcohol before arrest, their reports would reflect the relative frequency distribution of arrested drinking drivers across drinking places. All else being equal, these reports reveal the primary sources of drinking drivers on the road (by premise) and, should sales data be available, the beverage or beverages most strongly associated with drinking and driving. In the current study, these data were made available for the metropolitan area of Perth, Western Australia, covering a 4-year period, 1990 through 1993. Using these data, the goal of the present study was to ascertain the relationships between on-premise types, beverage sales and reports of place-of-last-drink using cross-sectional and time series data.

Method 


\section{Beverage Sales and Drinking and Driving: The Role of On-Premise Drinking Places.}

The units of analysis for the study were on-premise establishments $(N=57)$ with premise specific sales data and referrals for place-of-last-drink tracked over 4 years $(T=4)$. In total, during this period of time, 2,411 drinking and driving events occurred that resulted in an accident or a police stop involving drivers whose place of last drink was one of these 57 premises: $196(8.1 \%)$ of these events occurred in the context of a crash and 2,215 (91.9\%) occurred independently of a crash (i.e., during traffic-related stops by police). When this study was viewed as a cross-sectional analysis of 57 premises, it was expected that some "common-sense" relationships would appear: outlets with greater sales of any alcoholic beverage would have greater likelihood of being identified as a place-of-last-drink and some premise types (e.g., nightclubs or cabarets; Beel et al., 1993) would in general be more likely to produce more drinking drivers than others. When the study was viewed as a time series analysis of a set of cross-sections ( $\mathrm{N} x \mathrm{~T}=228$; Hsiao, 1986), it was expected that longitudinal variations in some beverage specific sales (e.g., beer in general and high alcohol beer in particular) would be more closely related to drinking and driving than sales of other beverage types.

The study area covered the Perth inner city including the suburbs of Perth, Northbridge, Highgate, East Perth and West Perth. This area contains 39 hotels or taverns and 18 cabarets which were continuously licensed over the 4 financial years of the study (1 July to 30 June, inclusive, for the years 1989-90, 1990-91, 1991-92, 1992-93). Five additional premises (three hotels and two cabarets) were not included in the sample due to incomplete data for 1 or more years. Hotel and tavern licenses enable the licensee to sell alcohol on the premises and to sell for consumption off the premises via a "bottleshop" and, during the study period, these establishments were allowed to remain open from 6 AM to 12 midnight. The only difference between hotels and taverns was that hotels were required to provide overnight accommodation. Throughout this article any reference to hotels also includes taverns. The holders of cabaret licenses are required to provide continuous entertainment and are permitted to remain open from 6 PM to 6 AM. Other licensed premises, such as restaurants, clubs and international hotel complexes, were excluded from the study because previous research has shown that these are rarely mentioned as places where drinking drivers consumed their last drink (so-called "low risk" outlets; Stockwell et al., 1992b).

Data on premise specific alcohol sales by beverage categories were provided to the National Centre for Research into the Prevention of Drug Abuse by the Liquor Licensing Division of Western Australia. These data were converted to pure ethanol sales (by volume) for each premise in each study year. Conversion factors representing the average alcohol content (\% by volume) for each beverage type were applied to sales totals to obtain total milliliters of absolute alcohol sold per year $(4.8 \%$ for high alcohol beer, 3.5\% for low alcohol beer, $11.9 \%$ for high alcohol wine, $6.0 \%$ for low alcohol wine and $38.5 \%$ for spirits) and this figure was multiplied by 0.79 to convert milliliters to grams of absolute alcohol (see Beel et al., 1993). Given the very small amount of low alcohol wine sold during the time of the study (less than $1 \%$ of all wine sales), only total wine sales were considered in the current analyses.

Since mid-1989 all drivers stopped for a preliminary breath test in Western Australia have been asked to name their place-of-last-drink. Preliminary breath tests are collected in all accident cases and all traffic-related stops in which police suspect alcohol use. During the period of study some $93 \%$ of all drivers reported an identifiable place-of-last-drink. This information, along with breath-test results, was obtained from the Western Australia Police Department. All drivers with a preliminary roadside breath test of $0.05 \%$ or over blood alcohol concentration (BAC) during the 4-year period who named one of the 57 licensed premises as place-of-last-drink were counted in the analysis. The $0.05 \%$ BAC was chosen to provide a consistent sample of respondents across the time period of study and to avoid biases due to the change to 0.05\% BAC as the drunk-driving cutoff in Western Australia as of June 1993. (In preliminary tests it was determined that the change to the $0.05 \%$ BAC had no statistically significant effects on the outcomes of the current study.) Counts of drinking drivers stopped with BACs of $0.05 \%$ or over were aggregated by premise identifications, including only the 57 licensed premises in the study. Thus, the dependent measure in the study was the number of drinking drivers naming each establishment as the place-of-last-drink. Preliminary examinations of the distribution of this dependent variable indicated that a power transformation ([square root of] $\mathrm{x}$ ) was sufficient to provide conditionally normal distributions of residuals in each analysis.

Data on two potentially confounding cross-sectional premise characteristics were obtained through contacts with managers of hotels: whether or not each hotel had a bottleshop (for sales off-premise) and the approximate proportion of sales on-premise. Premises without a bottleshop were asked if they sold "take-away" alcohol over the bar. From this information an approximate figure was derived to account for on-premise sales of alcohol. It was assumed that this estimate was relatively consistent over the 4 years of the study. The validity of the manager's bottleshop sales estimates 


\section{Beverage Sales and Drinking and Driving: The Role of On-Premise Drinking Places.}

has previously been tested and confirmed (Stockwell et al., 1992b). Of the hotels, 59\% did not have bottleshops, $15 \%$ had small bottleshops with an average of $5 \%$ off-premise sales and the remaining hotels averaged $50 \%$ of total sales through bottleshops (ranging from 11\% to 91\%). Cabarets do not have bottleshops, or across-bar sales.

Analysis procedures

Cross-sectional and time series cross-sectional analyses of the place-of-last-drink data were executed using ordinary least squares (OLS) and least squares dummy variable regression models (LSDV), respectively. The less efficient LSDV approach to analyzing the time series cross-sectional data was selected over more efficient random effects models based on the results of Hausman specification tests (Hsiao, 1986). Results of random effects models were biased relative to the consistent asymptotic estimates presented by LSDV models. Application of the LSDV model entailed regressing out of each model all unit effects ( $N=57$, to control for unit heterogeneity) and time effects $(T=4$, to control for aggregate temporal trends) prior to testing for the effects of remaining variables.

Three separate analyses were conducted for the three outcomes: all events, accident-related events and nonaccident-related events. While nonaccident-related events would likely be related to police activity (perhaps patrolling selected portions of the Perth area), accident-related events would be less so. Out of the 228 potential observations, nine were missing because of closure of these establishments early in the fourth year of the study $(n=219)$. Residuals from both OLS and LSDV analyses were examined for outlying and highly leveraged cases (Cook and Weisberg, 1982). No highly leveraged cases were found in any analysis. Five significant outliers (Student's $t$ [is greater than] |3|) were detected in the analysis that included all cases. Supplementary analyses of all three outcomes with these cases excluded were virtually the same as the original analyses. The original analyses are reported here.

Results

The upper portion of Figure 1 outlines the overall changes in alcohol sales by beverage type across the 4 years of the study. As shown by the stacked bars in the figure, there was a general decline in beverage sales. The stacked bars also indicate that sales by beverage type shifted somewhat over this period of time, reflected in a declining market for high alcohol beers and spirits. The lower portion of Figure 1 outlines four examples of premise specific changes. Here the four graphs indicate the wide variation observed in sales of alcohol between establishments over time. The premise represented in the graph to the upper left showed sporadic growth in sales of all beverage types. The premise represented in the graph to the upper right showed overall greater alcohol sales than that to its left with decreases in high alcohol beer and spirits sales over time. The premise represented in the graph to the lower left showed overall lesser alcohol sales than those above with an essentially flat pattern over time. The premise represented in the graph to the lower right showed wide variation in total sales, declining to near zero in 1991-92 and recovering in 1992-93, with a pattern dominated by shifts in spirits sales. Clearly, there was substantial cross-sectional and longitudinal variation in sales between premises.

\section{[Figure 1 ILLUSTRATION OMITTED]}

Table 1 presents the results of the cross-sectional analysis of all place-of-last-drink data over the 4 years of the study. Variables included in the OLS regression model were a constant term, effects-coded dummy variables for on-premise types (hotels, taverns, with cabarets as the omitted category), an effects-coded variable indicating whether (1) or not (-1) there was a bottleshop on-premise, average proportion of on-premise volume over the course of the study, beer sales, wine sales and spirits sales (in grams pure ethanol x 1,000) over the course of the study, and the average proportion of high alcohol beer sold.

TABLE 1. Cross-sectional analyses over 4 financial years

Dependent measures

All events

Variable $\quad b \quad t \quad p$ 


\section{Places.}

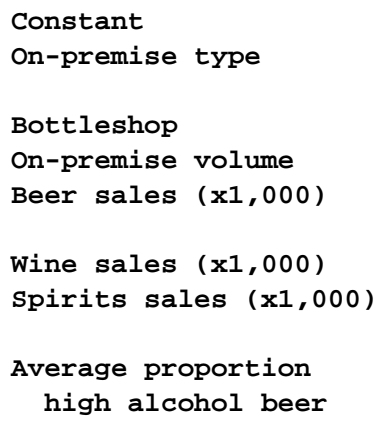

\begin{tabular}{|c|c|c|c|}
\hline & 2.246 & 0.529 & 0.299 \\
\hline (1) & -0.823 & -1.549 & 0.064 \\
\hline \multirow[t]{7}{*}{ (2) } & -1.079 & -2.091 & $.021(*)$ \\
\hline & 0.111 & 0.274 & 0.392 \\
\hline & 0.365 & 0.152 & 0.440 \\
\hline & 0.190 & 2.981 & $\begin{array}{l}.002 \text { ( [double } \\
\text { dagger] })\end{array}$ \\
\hline & -0.420 & -2.571 & .007 ([dagger]) \\
\hline & 0.460 & 3.393 & $\begin{array}{c}<.001([\text { double } \\
\text { dagger }])\end{array}$ \\
\hline & -0.176 & 0.044 & 0.582 \\
\hline
\end{tabular}

Dependent measures

Nonaccident events

Variable

b

t $\quad p$

Constant

On-premise type

(1)

2.648

0.630

0.266

(2)

$-1.086$

$-1.587$

0.060

$-2.128$

$.019(*)$

Bottleshop

On-premise volume

Beer sales $(x 1,000)$

Wine sales $(x 1,000)$

Spirits sales $(x 1,000)$

Average proportion

high alcohol beer

0.276

0.304

0.386

0.190

0.454

.002 ( [ double

dagger])

$\begin{array}{lll}-0.410 & -2.521 & .008 \text { ([dagger]) }\end{array}$

$\begin{array}{llll}0.440 & 3.271 & .001 \text { ([double }\end{array}$

dagger])

$\begin{array}{lll}-0.701 & -0.178 & 0.429\end{array}$

Dependent measures

Accident events

Variable

Constant

b

$t$

p

On-premise type

Bottleshop

On-premise volume

Beer sales $(x 1,000)$

Wine sales $(x 1,000)$

Spirits sales $(x 1,000)$

(1) $\quad-1.318 \quad-0.773 \quad .222$

(2)

-0.068
-0.101

0.029

$-0.321$

.374

0.029

.314

0.050

$0.179 \quad .429$

$-0.100$

0.489

.313

-0.100
0.160

1.827

$.037(*)$

0.160

$-1.553$

.064

.002 ( [double

Average proportion

high alcohol beer

$\begin{array}{lll}1.725 & 1.079 \quad .143\end{array}$

$\left(^{*}\right) p<.05 ;([$ dagger $]) p<01 ;([$ double dagger $]) p<.005$.

As the table shows for all drink-driving events, greater numbers of referrals for place-of-last-drink occurred for those establishments that sold greater quantities of beer and spirits and lesser quantities of wine. An $\mathrm{F}$ test of the combined effects of on-premise types was marginally significant $(F=3.112,2 / 48 \mathrm{df}, p=.054)$ and the test for taverns was significant, indicating that cabarets were somewhat more often, and taverns somewhat less often, referred to as the place-of-last-drink. There was no significant effect for overall proportion of high alcohol beer sold across the 4 years of the study.

Separate analysis of the nonaccident events demonstrated that both the on-premise type and alcohol sales effects were 


\section{Beverage Sales and Drinking and Driving: The Role of On-Premise Drinking Places.}

maintained for this outcome (on-premise types $F=3.235,2 / 48 \mathrm{df}, p=.048$ ). However, separate analysis of the accident events demonstrated that the on-premise type effect was not significant for this outcome $(F=.156,2 / 48 \mathrm{df}, p=.856)$ and that the beverage sales effects were restricted to premises that sold larger quantities of spirits and, less so, larger quantities of beer. The effect of wine sales was not significant. It is interesting to note that, although not significant, the sign of the effect for high alcohol beer changed from negative in the analysis of nonaccident events to positive in the analysis of accident events.

Table 2 presents the results of the time series cross-sectional analysis of place-of-last-drink data for the 57 establishments in the study. Not shown in the table were the significant effects for unit dummy variables regressed out of the data prior to analysis for each of the three dependent measures (all events: $F=13.637,56 / 161 \mathrm{df}, p$ [is less than] .001 , [R.sup.2] = .825; nonaccident events: $F=13.371,56 / 161 \mathrm{df}, \mathrm{p}$ [is less than] .001 , [R.sup.2] = .822; accident events: $\mathrm{F}=4.156,56 / 161 \mathrm{df}, \mathrm{p}$ [is less than] .001, [R.sup.2] = .590). Presented in the table are the measures of beer, wine and spirits sales, proportion of high alcohol beer sold, effects-coded dummy variables representing time trend effects for study years (the fourth year is the omitted category), and the measure of temporal autocorrelated errors in residuals, p. Purely cross-sectional variables (i.e., on-premise type dummies, the bottleshop indicator, and on-premise volume sold) were perfectly collinear with unit

effects and so excluded from the model.

TABLE 2. Time series cross-sectional analyses over 4 financial years

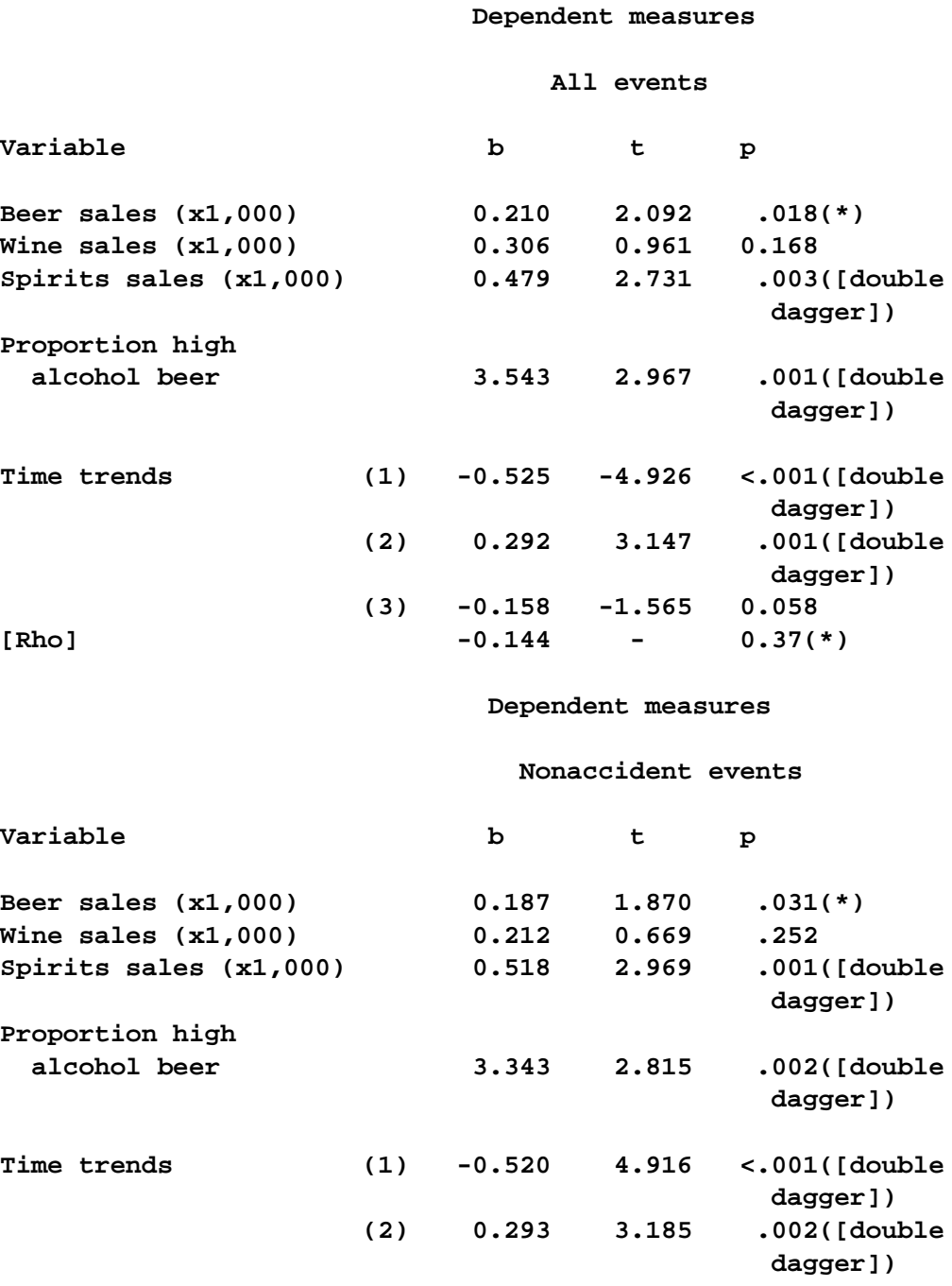




\section{Beverage Sales and Drinking and Driving: The Role of On-Premise Drinking} Places.

\begin{tabular}{|c|c|c|c|c|}
\hline \multirow{3}{*}{ [Rho] } & (3) & -0.140 & -1.395 & .082 \\
\hline & & -0.200 & - & .007 ([dagger $]$ ) \\
\hline & \multicolumn{4}{|c|}{ Dependent measures } \\
\hline & \multicolumn{4}{|c|}{ Accident events } \\
\hline Variable & & b & $t$ & $p$ \\
\hline Beer sales $(x 1,000)$ & & 0.160 & 2.407 & .009 ([dagger $]$ ) \\
\hline Wine sales $(x 1,000)$ & & 0.178 & 0.845 & 0.188 \\
\hline Spirits sales $(x 1,000)$ & & -0.068 & -0.586 & 0.279 \\
\hline \multicolumn{5}{|l|}{ Proportion high } \\
\hline alcohol beer & & 1.194 & 1.511 & 0.066 \\
\hline \multirow[t]{3}{*}{ Time trends } & (1) & -0.139 & -1.975 & $.025(*)$ \\
\hline & (2) & 0.009 & 0.155 & 0.438 \\
\hline & (3) & -0.006 & -0.005 & 0.466 \\
\hline [Rho] & & -0.152 & - & $.029(*)$ \\
\hline
\end{tabular}

Note: [Rho] $p$ tested with $z=|[R h o]|[$ square root of $N(t-1)-[n . s u b . m]-k], N=57$ units, $t=4$ years, [n.sub.m] = nine missing observations, $k=7$ df; Judge et al., 1985, p. 394.

$\left(^{*}\right) p<.05 ;([$ dagger $]) p<.01 ;([$ double dagger $]) p<.005$.

The results of these analyses show, first of all, that there were substantive overall time trend effects in the data. The first and second years of observation presented significantly lower, then higher, rates of place-of-last-drink referrals (because there were lesser and greater numbers of stops during those years). The estimated coefficient for the fourth year was $b=$ .391, greater again. After controlling for these time trend effects, and all effects attributable to exogenous differences between establishments, greater sales of beer and spirits were both significantly related to greater frequencies of referral as place-of-last-drink, and the proportion of high alcohol beer sold was significantly related to greater frequencies of referral as place-of-last-drink. That is, premises that sold more spirits and beer, and greater proportions of high alcohol beer, were more likely to be referred to as the place-of-last-drink by drivers with BACs greater than or equal to $0.05 \%$.

Several supplementary analyses of these data were conducted to further explore these results. As indicated at the bottom of the table, there were significant temporal autocorrelated errors in estimate in each of the models. Although not a source of bias to coefficient estimates (Judge et al., 1985), these effects do reduce the efficiencies of the models. Incorporation of a Cochrane-Orcutt adjustment for autocorrelated error did not substantively alter the effects estimates of the models but did dramatically reduce, rather than enhance, model efficiency. This was due to the rather dramatic loss of degrees of freedom accompanying this adjustment procedure (an additional 57 degrees of freedom; Greene, 1993). Terms relating to the interaction of on-premise types with alcohol sales were also included in supplementary analyses to detect premise specific sales effects. Tests of the contribution of these additional 14 degrees of freedom to each model proved not significant in each case for all events $(F=1.202,14 / 141 \mathrm{df}, p=.465)$, nonaccident events $(F=1.310,14 / 141 \mathrm{df}, p=.434)$ and accident events $(F=1.221,14 / 141 \mathrm{df}, \mathrm{p}=.442)$.

Discussion

The results of the current study supported expectations expressed in the literature regarding the roles of drinking premises and beverage types in drinking and driving. The cross-sectional analyses supported the not surprising suggestion that the greater the amount of alcohol sold within establishments the greater the frequency with which those outlets will be referred to as the place-of-last-drink by drinking drivers. Greater beer and spirits sales were related to greater frequencies of referral as place-of-last-drink for all events, nonaccident events and accident-related drinking and driving events. In addition, these analyses supported the suggestion that, independent of the effects of beverage sales, certain premise types produced more drinking drivers than others. Here cabarets were most likely, and taverns least likely, to be referred to as places-of-last-drink (focused on nonaccident-related drinking-driver stops; Table 1). Accident-related events appeared strongly related to sales of beer and spirits but were undifferentiated with respect to 


\section{Beverage Sales and Drinking and Driving: The Role of On-Premise Drinking Places.}

premise type per se. This finding suggests that, although they are associated with likelihoods of drinking and driving (perhaps extending uniquely to cabarets because of their later closing hours), premise types are not associated with likelihoods of drinking and driving and crashing.

As suggested in the introduction, the combined use of cross-sectional and time series cross-sectional analyses in the study of these place-of-last-drink data further illuminated the relationships between locations of drinking and drinking and driving. Thus, controlling for all exogenous differences between on-premise establishments (by regressing out all unit specific effects), the LSDV analyses of the time series cross-sections revealed significant relationships between places-of-last-drink and sales of beer, spirits and high alcohol beer over the course of 4 years of study. In general, establishments that increased beer sales were more likely to be named as a place-of-last-drink, establishments that increased spirits sales were more likely to be named as a place-of-last-drink and establishments that sold greater proportions of high alcohol beer were more likely to be named as a place-of-last-drink. In the case of beer sales these effects extended across nonaccident- and accident-related events. In the cases of spirits sales and proportion of high alcohol beer sold these effects extended only to nonaccident events.

The observation of an effect of proportion of high alcohol beer sold upon frequencies of referral as place-of-last-drink among nonaccident observations provides some support for suggestions in the literature that the alcohol content of beers may be an important ingredient in affecting a change in drinking and driving. Provision of low alcohol beers may prove a potent means of reducing drinking and driving in states in which consumption of high alcohol beers predominates $(81 \%$ of all beer consumed in Australia in 1990-91; Commonwealth Department of Health, Housing and Community Services, 1992). Among other things, the provision of a lower alcohol beer alternative may result in a substitution of lower strength alcohol for higher strength alcohol without a reduction in the fluid volume of alcohol sold (and hence without a reduction in the commercial viability of licensed premises). The substitution of "low" for "high" can be seen as a win/win situation for public health professionals, the government and the alcohol industry. This suggestion should be made, however, with some caution. Considering the more specific drinking and driving outcome, accidents in which the drivers' BAC exceeded $0.05 \%$, the effect for proportion high alcohol beer was obtained with significance $p=.066$ (Table 2).

Although these results appear to support a relatively standard view of relationships between beverage preferences, premise types and drink-driving, one that suggests that certain premises are more or less likely to be associated with drinking and driving and that drinking drivers express unique beverage preferences, the results must nevertheless be viewed with some consideration given to the unique sampling characteristics of the study. As noted in the Results section, the number of drinking drivers stopped will be affected by the level of police breath-testing enforcement (here reaching a peak in the 1990-91 period). While over the period of study the overall level of enforcement remained relatively constant (in terms of number of drivers stopped, number of drivers tested and number of police hours worked; Beel et al., 1993), the focus of police discretion in deciding who is breath tested remains a sampling concern. The effects of year-to-year enforcement fluctuations will be captured in the year dummy variables applied in the LSDV model; however, unobserved correlations between enforcement patterns and premise types over the years of the study may affect the distribution of referrals to place-of-last-drink. Thus, police may choose to differentially enforce breath testing in areas of the community in which they suspect drinking driving to be likely (e.g., around cabarets during late night periods). To the extent that these effects are constant over the years of the study, they are regressed out of the LSDV analysis. To the extent that these effects vary over the years of the study, they remain an unobserved con-founder in these analyses.

\section{References}

BEEL, A., STOCKWELL, T. AND DYSKIN, E.V. Drink driving and consumption of low alcohol beer by hotel and nightclub patrons. Paper presented at the Australian Drink-Drive Conference, World Congress Centre, Melbourne, Australia, November 22-23, 1993.

BERGER, D.E. AND SNORTUM, J.R. A structural model of drinking and driving: Alcohol consumption, social norms, and moral commitments. Criminology 24: 139-153, 1986.

BORKENSTEIN, R.F., CROWTHER, R.F., SHUMATE, R.P., ZIEL, W.B. AND ZYLMAN, R. The Role of the Drinking Driver in Traffic Accidents, Bloomington: Dept. of Police Administration, Indiana University, 1964. 


\section{Beverage Sales and Drinking and Driving: The Role of On-Premise Drinking Places.}

CASSWELL, S., ZHANG, J.F. AND WYLLIE, A. The importance of amount and location of drinking for the experience of alcohol-related problems. Addiction 88: 1527-1534, 1993.

COMMONWEALTH DEPARTMENT OF HEALTH, HOUSING AND COMMUNITY SERVICES. Statistics on Drug Abuse in Australia, 1992, Canberra: Australian Government Publishing Service, 1992.

COOK, R.D. AND WEISBERG, S. Residuals and Influence in Regression, New York: Chapman and Hall, 1982.

GREENE, W.H. Econometric Analysis, 2nd Edition, New York: Macmillan Publishing Co., Inc., 1993.

GRUENEWALD, P.J., TRENO, A.J., NEPHEW, T.M. AND PONICKI, W.R. Routine activities and alcohol use: Constraints on outlet utilization. Alcsm Clin. Exp. Res. 19: 44-53, 1995.

HAWORTH, N. AND RECHNITZER, G. Description of Fatal Crashes Involving Various Causal Variables, Report No. CR 119, Canberra, Australia: Federal Office of Road Safety, 1993.

HSIAO, C. Analysis of Panel Data, New York: Cambridge Univ. Press, 1986.

JUDGE, G.G., GRIFFITHS, W.E., CARTER HILL, R., LUTKEPOHL, H. AND LEE, T.-C. The Theory and Practice of Econometrics, 2nd Edition, New York: John Wiley \& Sons, Inc., 1985.

LANG, E. AND STOCKWELL, T. Drinking locations of drink-drivers: A comparative analysis of accident and nonaccident cases. Accid. Anal. Prey. 23: 573-584, 1991.

MAKKAI, T. AND MCALLISTER, I. Patterns of Drug Use in Australian Society, Department of Health, Housing, Local Government and Community Services, Canberra, Australia: Australian Government Printer, 1993.

PERRINE, M.W. Identification of personality, attitudinal, and biographical characteristics of drinking drivers. Behav. Res. Highway Saf. 1: 207-226, 1970.

SELZER, M.L., VINOKUR, A. AND WILSON, T.D. A psychosocial comparison of drunken drivers and alcoholics. J. Stud. Alcohol 38:1294-1312, 1977.

SINGLE, E. AND WORTLEY, S. Drinking in various settings as it relates to demographic variables and level of consumption: Findings from a national survey in Canada. J. Stud. Alcohol \$4: 590-599, 1993.

SNORTUM, J.R., KREMER, L.K. AND BERGER, D.E. Alcoholic beverage preference as a public statement: Self-concept and social image of college drinkers. J. Stud. Alcohol 48: 243-251, 1987.

STOCKWELL, T, LANG, E. AND RYDON, P. High risk drinking settings: The association of serving and promotional practices with harmful drinking. Addiction 88:1519-1526, 1993.

STOCKWELL, T., RYDON, P., GIANATTI, S., JENKINS, E., OVENDEN, C. AND SYED, D. Levels of drunkenness of customers leaving licensed premises in Perth, Western Australia: A comparison of high and low risk premises. Brit. J. Addict. 87: 873-881, 1992a.

STOCKWELL, T., SOMERFORD, P. AND LANG, n. The relationship between license type and alcohol-related problems attributed to licensed premises in Perth, Western Australia. J. Stud. Alcohol 53: 495-498, 1992b.

Received: October 21, 1996. Revision: May 14, 1997.

$\left({ }^{*}\right)$ Research for and preparation of this article were conducted in part while the first author was a Visiting Fellow at the National Centre for Research into the Prevention of Drug Abuse, Curtin University of Technology, Perth, Western Australia. 
Beverage Sales and Drinking and Driving: The Role of On-Premise Drinking

\section{Places.}

([dagger]) Tim Stockwell, Andrea Beel and Elena V. Dyskin are with the National Centre for Research into the Prevention of Drug Abuse, Curtin University of Technology, Perth, Western Australia.

PAUL J. GRUENEWALD, PH.D., TIM STOCKWELL, PH.D.,([dagger]) ANDREA BEEL, M.A.,([dagger]) AND ELENA V. DYSKIN, B.A.([dagger]) Prevention Research Center, 2150 Shattuck Avenue, Suite 900, Berkeley, California 94704 